\title{
COVID-19 outbreak, disruption of dental education, and the role of teledentistry
}

\author{
Imran Farooq ${ }^{1}$, Saqib Ali ${ }^{2}$, \\ Imran Alam Moheet ${ }^{3}$, Jehan AlHumaid ${ }^{4}$
}

\begin{abstract}
The novel coronavirus disease 2019 (COVID-19) has affected the whole world and has now been declared a Pandemic by the World Health Organization (WHO). Although the mortality rate of this virus is low, it is especially potent against people with underlying systemic conditions. Dentistry is a profession where the doctor, as well as the dental staff, works in close vicinity to the patient's mouth. Dental education has two core components; didactic and clinical training (including patient care). Dental education has been interrupted in the past due to certain events (Arab Spring and SARS outbreak). Currently, the pandemic of COVID-19 has disrupted dental education globally as most of the dental schools and universities in the world have closed amidst the COVID-19 outbreak. Teledentistry is a subspecialty of telemedicine that helps in the provision of educational activities, advice, and diagnosis about treatment over a distance with the help of technology like video conferencing. The current overview summarizes the potential role of teledentistry in continuing the dental educational process in terms of delivery of didactic components, clinical training, and patient care. It can be concluded that with modern updated devices and tools, teledentistry can be an effective way to prevent disruption of dental education and it can be utilized in continuing the dental educational process in this critical time of the COVID-19 outbreak.
\end{abstract}

KEYWORDS: Clinical, COVID-19, Dental education, Didactic, Teledentistry, Patient care.

doi: https://doi.org/10.12669/pjms.36.7.3125

How to cite this:

Farooq I, Ali S, Moheet IA, AlHumaid J. COVID-19 outbreak, disruption of dental education, and the role of teledentistry. Pak J Med Sci. 2020;36(7):1726-1731. doi: https://doi.org/10.12669/pjms.36.7.3125

This is an Open Access article distributed under the terms of the Creative Commons Attribution License (http://creativecommons.org/licenses/by/3.0), which permits unrestricted use, distribution, and reproduction in any medium, provided the original work is properly cited.

1. Imran Farooq,

Department of Biomedical Dental Sciences,

2. Saqib Ali,

Department of Biomedical Dental Sciences,

3. Imran Alam Moheet,

Azra Naheed Dental College,

Superior University,

Lahore, Pakistan.

4. Jehan AlHumaid,

Department of Preventive Dental Sciences,

1,3,4: College of Dentistry,

Imam Abdulrahman Bin Faisal University,

Dammam, Saudi Arabia.

Correspondence:

Imran Farooq,

Assistant Professor,

Department of Biomedical Dental Sciences,

College of Dentistry,

Imam Abdulrahman Bin Faisal University,

Dammam 31441, Saudi Arabia.

Email: drimranfarooq@gmail.com

* Received for Publication:

June 11, 2020

* Revision Received:

* Revision Accepted:

August 10, 2020

\section{INTRODUCTION}

The novel coronavirus disease 2019 (COVID-19) came into attention after the first case was reported in December 2019 in Wuhan China. ${ }^{1}$ It has since then affected almost all countries in the world and has been declared a Pandemic by the WHO. ${ }^{2}$ This virus belongs to coronavirus family which has similar morphology and structure to severe acute respiratory syndrome (SARS) and the Middle East respiratory syndrome (MERS) viruses. ${ }^{3}$ Although the mortality rate of this virus is low, it is especially potent against people with underlying systemic conditions. ${ }^{4}$ According to a recent study, the median incubation period of this virus is 4.5-5.8 days, and $97.5 \%$ people getting this infection will develop symptoms within 11.5 days. ${ }^{5}$ Typical symptoms of COVID-19 include cough, fever, fatigue, diarrhoea, haemoptysis, myaligia, dyspnoea, and pneumonia. ${ }^{6}$ The reported transmission of

\footnotetext{
$\begin{array}{lllll}\text { Pak J Med Sci November-December } 2020 & \text { Vol. } 36 & \text { No. } 7 \quad \text { www.pjms.org.pk } 1726\end{array}$
} 
this disease is from person to person, touching of surfaces contaminated with the virus, or its spread through respiratory droplets. ${ }^{2}$ Currently, work is undergoing to find a cure for this disease but to date, there is no vaccine available for COVID-19.

Dentistry is a profession where the doctor, as well as the dental staff, works in close vicinity to the patient's mouth. ${ }^{7}$ Most of the treatment procedures in dentistry generate aerosols which could lead to transmission of the virus from patients to the dental staff and vice versa. ${ }^{8}$ Therefore, most of the dental regulatory bodies globally have advised dentists to practice extreme caution while treating patients and provide emergency dental care only in this critical time of the COVID-19 outbreak. $^{2}$ The Bachelor of Dentistry (B.D.S) degree program normally comprises of four years of formal education while in some countries, it can span over a period of six years. ${ }^{9}$ Dental education is usually divided into two parts i.e. pre-clinical and clinical years. ${ }^{10}$ In the pre-clinical years, students are mostly studying basic science subjects didactically and their practical work is restricted to dental laboratories where they practice on the phantom head/extracted teeth. ${ }^{11}$ In the clinical years, students have a bit of didactic part but most of their work is based in the clinical environment, where they work on real patients under the supervision of specialist doctors. ${ }^{12}$

\section{DISRUPTION OF DENTAL EDUCATION AND TRAINING IN THE PAST}

The outbreak of COVID-19 has disrupted dental education globally as most of the dental schools and universities in the world have closed amid COVID-19 pandemic. Unfortunately, this is not the first-time dental education has been disrupted. Few past examples when this happened before are summarized below.

Disruption of dental education and training during the Arab Spring: In the Arab world, Egypt is one of the countries that has the most number of universities. ${ }^{13}$ In 2011, Egypt faced the Arab Spring due to political unrest in the country. ${ }^{14}$ This resulted in the closure of dental schools and many Malaysian dental students who were studying there were called back by their government. ${ }^{15}$ These students upon their return faced problems like safe return, the difference in the curriculum, high tuition costs, and credit transfer. ${ }^{15}$

Disruption of dental education and training during the SARS outbreak: In 2003, a new type of pneumonia with high levels of infectivity surfaced globally and was called SARS. ${ }^{16}$ Typical symptoms of SARS included fever, chills, headache, sore throat, dyspnoea, and hypoxia. ${ }^{17}$ Approximately 8,000 active cases of SARS were reported resulting in 800 deaths worldwide. ${ }^{18}$ In March 2003, clinical teaching in the dental hospital of Hong Kong University was immediately ceased. ${ }^{19}$ This decision was based on the emerging reports that 17 medical students from the Faculty of Medicine, Chinese University of Hong Kong had already acquired SARS..$^{19}$ After disruption of almost a month, the didactic teaching resumed on $14^{\text {th }}$ April 2003 whereas the clinical training started 10 days after that in Faculty of Dentistry, Hong Kong University. ${ }^{20}$ It should be noted that, even after the recommencement of educational activities, instructions were given to keep the group teaching to a minimum and to follow strict infection control protocols in the clinics. ${ }^{20}$

\section{TELEDENTISTRY'S ROLE IN CONTINUING DENTAL EDUCATION AND TRAINING AMID COVID-19 OUTBREAK}

From past experiences, it has been learned that dental education is interrupted whenever there is a crisis like war, political unrest, or a disease outbreak. The same situation has ascended with the COVID-19 outbreak where educational institutes (including dental schools) have been closed globally in an effort to restrain the spread of this disease. At this time of crisis, the role of online education becomes very important in dentistry. One synonymous term which was introduced in the past called "teledentistry" has a major role to play in this critical time. In this article, we have used the term teledentistry synonymously with eLearning or online education, whenever dental education is being discussed.

Origin of teledentistry: Dentistry has seen extensive innovations in technology in the past decade. These innovations include the use of computers, digital diagnostic imaging, digital models, digital planning and designing, and software use for analysis and follow up..$^{21}$ Teledentistry as a subspecialty of telemedicine was introduced in 1994 as part of a military project to improve patient care and dental education by the United States (U.S.) Army. ${ }^{22}$ This project reported that by introducing teledentistry, there was a reduction in patient care costs and it enabled them to extend dental care to distant rural areas. ${ }^{22}$ The term "Teledentistry" could be defined as the provision of advice and diagnosis about treatment over a distance with the help of technology like video conferencing. ${ }^{23}$ Teledentistry 
can also be used to provide online formal education in the form of web-based self-instructions or interactive video conferencing. ${ }^{24}$ The potential role of teledentistry in continuing dental educational activities (didactic and clinical) amid the COVID-19 outbreak is discussed below in detail.

Role of teledentistry in delivering didactic component of dental education: Normally, didactic lectures are attended physically by students and are an essential component of dental education. ${ }^{25} \mathrm{It}$ is one of the most popular and commonly utilized for delivering conceptual information to a vast audience at one time. ${ }^{11}$ Unfortunately amid the COVID-19 outbreak, this method of teaching is seriously affected and educational sectors globally are shifting towards online educational tools. At this point, the role of teledentistry becomes indispensable as it can be used to take live interactive video lecture ${ }^{26}$ or a pre-recorded lecture (based on store-and-forward methodology). ${ }^{21}$ The advantages of the former method include live interaction and immediate feedback. ${ }^{27}$ Whereas the latter technique has its own benefits like the user can control the learning pace and can review learning material at their timing of choosing repeatedly. ${ }^{27}$ Through these two methods of teledentistry, lectures can be delivered, instructor and students can have a live interaction, see a demonstration or a prepared stored material, and case discussion can be completed as well. ${ }^{28}$ These two methodologies of teledentistry to deliver the didactic component of dental education are exemplified in Fig.1 and 2.

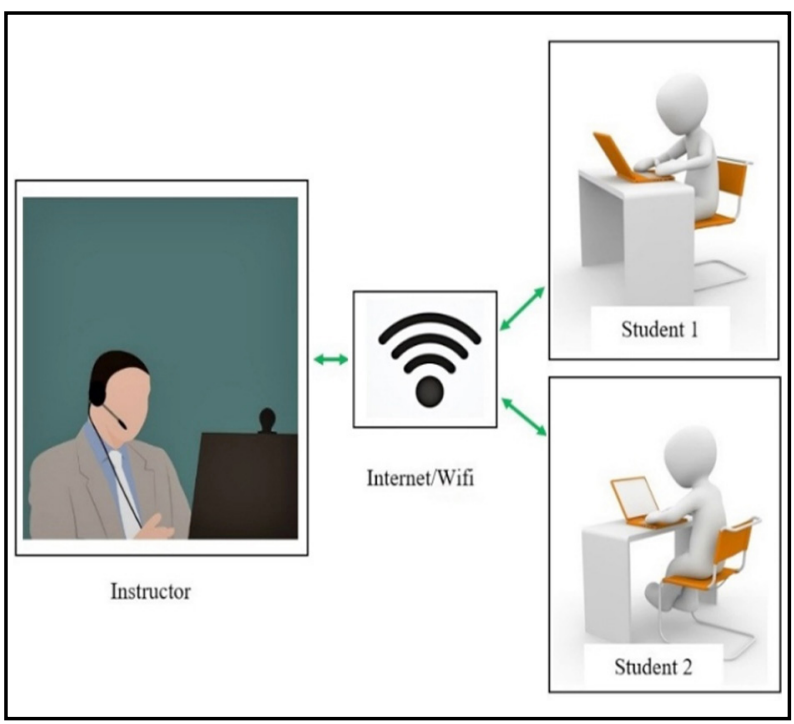

Fig.1: Showing live interactive video lecture technique to cover didactic component of dental education.
It is also important to mention that students of the current generation are technology savvy and they prefer online-educational tools over conventional face-to-face lectures. ${ }^{29}$ Farooq and Al-Jandan previously reported that lectures that use modern tools like videos for illustration of phenomenon's, can enhance students' learning. ${ }^{11}$ Post-COVID-19 pandemic when all the educational activities are ceased globally, teledentistry could prove to be a vital tool for continuing dental education and training, till the time we return to a normal world where physical distancing is no longer required.

Role of teledentistry in clinical training component of dental education: Teledentistry can be used to teach few aspects of the clinical training to the students. ${ }^{21}$ Certain clinical subjects in dental curriculum like orthodontics and oral radiology are well suited for teledentistry. ${ }^{27,}{ }^{30} \mathrm{In}$ these specialties, it is convenient to collect the patient data and then discuss it with the students via teledentistry tools, even in the physical absence of the patient. ${ }^{27}$ Teledentistry can aid in conducting problem-focused evaluations with students without the need for them to be present. ${ }^{28}$ The use of virtual patients (VPs) in mastering skills like patient interviewing abilities, history taking, and treatment planning has its own importance. ${ }^{31}$ Recently in a randomized controlled clinical trial, Seifert et al. (2019), reported that computerized VPs are an effective alternative to lecture led small group discussions in terms of learning effectiveness and learner's

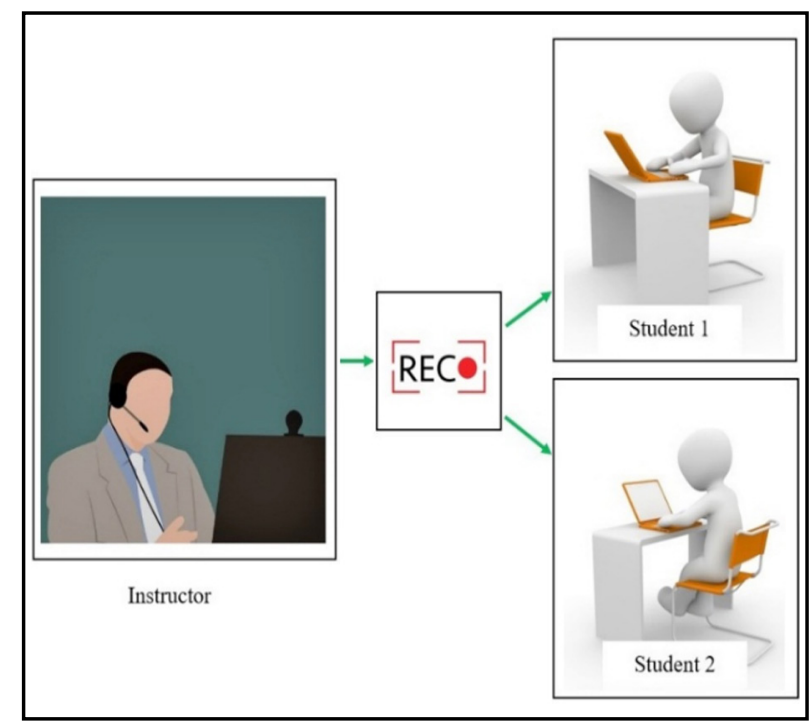

Fig.2: Showing pre-recorded lecture technique to cover didactic component of dental education. 
contentment. ${ }^{32}$ In the current scenario where the world is facing COVID-19 pandemic and risk of cross-infection from dental clinics is very high, the use of VPs to teach dental students could be very handy and effective.

Role of teledentistry in patient care: In the clinical years, dental students are required to treat patients with oral and dental problems under the supervision of subject specialist. ${ }^{33}$ During COVID-19 pandemic, it is need of the hour to triage patients before receiving them for emergency dental care in educational institutions, hospitals, and private clinics through teledentistry tools. ${ }^{2}$ For patient care, teledentistry covers a lot of ground for various dental problems. In prosthodontics, Ignatius E et al. (2010) demonstrated the use of video conferencing for prosthetic rehabilitation. ${ }^{34}$ The author reported that with these tools, dental services can be expanded to areas with scarce population as well. ${ }^{34}$ In Oral Medicine, TorresPereira et al. (2008) has shown that diagnosis of oral lesions can be made via digital images sent through an email..$^{35}$ The author reported that this is an effective tool in diagnosing patients from rural areas where a specialist is not available. ${ }^{35}$ In Oral and Maxillofacial Surgery, it has been previously reported that diagnosis of impacted third molar teeth assisted with telemedicine tools is equivalent to real-time clinical diagnosis. ${ }^{36}$ Teledentistry is also an effective tool in endodontics where diagnosis of periapical lesions can be made distantly. ${ }^{37}$ Hence, reducing the cost and number of visits for the patient. ${ }^{37}$ Stephens et al. in 2002 reported that orthodontic consultants support teledentistry to make their advice more available to the patients. ${ }^{38}$ The U.S. Department of Defence introduced a system called Total Dental Access (TDA) which helped dentists of US Armed Forces to connect with specialists to discuss patients cases. ${ }^{39}$ This system established that one of the maximum consultations were related to periodontal problems of patients. ${ }^{39}$ In the field of pediatric dentistry, teledentistry has proven its worth as it can be used as a useful tool to assess caries status in young children. ${ }^{40}$

Limitations of teledentistry: Teledentistry has certain limitations which include a) requirement of a proper internet connection b) the instructor being properly trained in delivering online educational activities and c) limited role to play in clinical training as it mostly involves hand-on practice. Other important considerations while utilizing teledentistry include protection of patient data, involvement of patient in decision making, and referral to appropriate specialist (if needed).

Limitations of the study: One of the limitations of our study was the inclusion of limited number of articles. However, it should be considered that teledentistry is relatively a new term which is still being evolved. Also, the pandemic of COVID-19 and the role of teledentistry has not been discussed much in the literature. These two points could justify the inclusion of 40 articles in our study. Another limitation was writing a narrative type review, rather than a metaanalysis or systematic review. Again, to defend this, the authors would like to point out towards the scarcity of data available in the current literature highlighting the role of teledentistry in continuing dental education amidst COVID-19 outbreak.

\section{CONCLUSION}

It can be concluded from the current overview that teledentistry can prove to be extremely useful in continuing dental educational activities during the time of COVID-19 outbreak. The current situation has opened the doors for an avenue which was less explored in the past. Teledentistry can help in the deliverance of all essential components of dental education. Teledentistry can also be used in daily practice where it can be beneficial as it would save consultation time for both dentist and patient. In addition, it can be used to triage patients in this critical time of COVID-19 pandemic, before receiving them for emergency dental care in educational institutions, hospitals, and private clinics through teledentistry tools.

Acknowledgements: The authors are grateful to the Deanship of Library Affairs, Imam Abdulrahman Bin Faisal University, Dammam, Saudi Arabia for providing us access to the full length of the articles included in this study.

Disclosure Statement: The authors declare no conflict of interest. 


\section{REFERENCES}

1. Ali S, Noreen S, Farooq I, Bugshan, A, Vohra, F. Risk assessment of healthcare workers at the frontline against COVID-19. Pak J Med Sci. 2020;36(COVID19S4):COVID19-S99-S103. doi: 10.12669/pjms.36. COVID19-S4.2790

2. Farooq I, Ali S. COVID-19 outbreak and its monetary implications for dental practices, hospitals and healthcare workers. Postgrad Med J. 2020;postgradmedj-2020-137781. doi: 10.1136/ postgradmedj-2020-137781

3. Paules CI, Marston HD, Fauci AS. Coronavirus infections - More than just the common cold. JAMA. 2020; 323(8):707708. doi: 10.1001/jama.2020.0757

4. Guo YR, Cao QD, Hong ZS, Tan YY, Chen SD, Jin HJ, et al. The origin, transmission and clinical therapies on coronavirus disease 2019 (COVID-19) outbreak - an update on the status. Mil Med Res. 2020;7(1):11. doi: 10.1186/ s40779-020-00240-0

5. Lauer SA, Grantz KH, Bi Q, Jones FK, Zheng Q, Meredith $\mathrm{HR}$, et al. The incubation period of coronavirus disease 2019 (COVID-19) from publicly reported confirmed cases: Estimation and application. Ann Intern Med. 2020;M200504. doi: 10.7326/M20-0504

6. Abbas Z, Zaheer R. Clinical insight into the involvement of gut and liver by COVID-19. J Pak Med Assoc. 2020;70(6):952-953.

7. Nagrik AP, Bhagat BA, YemleSB, Maidapwad S. Awareness of specialties of dentistry among medical trainees and teaching faculty of medical college in the Central West India. J Int Soc Prev Community Dent. 2019;9(3):269-274. doi: 10.4103/jispcd.JISPCD_297_18

8. Harrel SK, Molinari J. Aerosols and splatter in dentistry: a brief review of the literature and infection control implications. J Am Dent Assoc. 2004;135(4):429-437. doi: 10.14219/jada.archive.2004.0207

9. Komabayashi T, Raghuraman K, Raghuraman R, Toda S, Kawamura M, Levine SM, et al. Dental education in India and Japan: implications for U.S. dental programs for foreign-trained dentists. J Dent Educ. 2005;69(4):461-469. doi: 10.1002/j.0022-0337.2005.69.4.tb03934.x

10. Farooq I, Ali S. Comparison of the perceived relevance of oral biology reported by students and interns of a Pakistani dental college. Eur J Dent Educ. 2014;18(4):203206. doi: 10.1111 / eje. 12086

11. Farooq I, Al-Jandan BA. Effect of video triggering during conventional lectures on final grades of dental students in an oral biology course: A two-year retrospective study. J Dent Educ. 2015;79(12):1467-1470. doi: 10.1002/j.00220337.2015.79.12.tb06047.x

12. Horst JA, Clark MD, Lee AH. Observation, assisting, apprenticeship: cycles of visual and kinesthetic learning in dental education. J Dent Educ. 2009;73(8):919-933. doi: 10.1002/j.0022-0337.2009.73.8.tb04781.x

13. Unions Warn of Rise in Pharmacy, Dentistry Admissions. http: / / www.universityworldnews.com / article. php?story=20140822090434940 Accessed April 10, 2020

14. Brownlee BJ, Ghiabi M. Passive, silent and revolutionary: The 'Arab Spring' revisited. Middle East Crit. 2016;25(3):299-316. doi: 10.1080/19436149.2016.1177919

15. Simon SS, Ramachandra SS, Abdullah DD, Islam MN, Kalyan C. Lessons learned from the disruption of dental training of Malaysian students studying in Egypt during the Arab spring. Educ Health. 2016;29:124-127. doi: 10.4103/1357-6283.188753
16. Nie QH, Luo XD, Zhang JZ, Su Q. Current status of severe acute respiratory syndrome in China. World J Gastroenterol. 2003;9(8):1635-1645. doi: 10.3748/wjg. v9.i8.1635

17. Srikantiah P, Charles MD, Reagan S, Clark TA, Pletz MWR, Patel PR, et al. SARS clinical features, United States, 2003. Emerg Infect Dis. 2005;11(1):135-138. doi: 10.3201/ eid1101.040585

18. Wilder-Smith A, Chiew CJ, Lee VJ. Can we contain the COVID-19 outbreak with the same measures as for SARS? Lancet Infect Dis. 2020;20(5):102-107. doi: 10.1016/S14733099(20)30129-8

19. Smales FC, Samaranyake LP. Maintaining dental education and specialist dental care during an outbreak of a new coronavirus infection. Part 1: A deadly viral epidemic begins. Br Dent J. 2003;195(10):557-561. doi: 10.1038/sj.bdj. 4810723

20. Smales FC, Samaranyake LP. Maintaining dental education and specialist dental care during an outbreak of a new coronavirus infection. Part 2: Control of the disease, then elimination. Br Dent J. 2003;195(12):679-681. doi: 10.1038/sj.bdj.4810819

21. Jampani ND, Nutalapati R, Dontula BS, Boyapati R. Applications of teledentistry: A literature review and update. J Int Soc Prev Community Dent. 2011;1(2):37-44. doi: 10.4103/2231-0762.97695

22. Mihailovic B, Miladinovic M, Vujicic B. Telemedicine in Dentistry (Teledentistry) In: Graschew G, Roelofs TA, editors. Advances in Telemedicine: Applications in Various Medical Disciplines and Geographical Areas 2011. Rijeka (Croatia): InTech; 2011. pp. 215-230.

23. Fricton J, Chen H. Using teledentistry to improve access to dental care for the underserved. Dent Clin North Am. 2009;53(3):537-548. doi: 10.1016/j. cden.2009.03.005

24. Bhambal A, Saxena S, Balsaraf SV. Teledentistry: potentials unexplored! J Int Oral Health. 2010;2(3):1-6.

25. Farooq I. Interpretive versus didactic learning approach towards oral biology: a student's perspective. J Coll Physicians Surg Pak. 2014;24(10):772-774. doi: 10.2014/ JCPSP.772774

26. Baheti MJ, Bagrecha SD, Toshniwal NG, Misal A. Teledentistry: A Need of the Era. Int J Dent Med Res. 2014;1(2):80-91.

27. Chen JW, Hobdell MH, Dunn K, Johnson KA, Zhang J. Teledentistry and its use in dental education. J Am Dent Assoc. 2003;134(3):342-346. doi: 10.14219/jada. archive.2003.0164

28. Chhabra N, Chhabra A, Jain RL, Kaur H, Bansal S. Role of teledentistry in dental education: need of the era. J Clin Diag Res. 2011;5(7):1486-1488.

29. Al-Jandan BA, Farooq I, Khan SQ. Students' perspectives on the relevance of internet-based educational videos in dental education. J Taibah Uni Med Sci. 2015;10(3):288292. doi: 10.1016/j.jtumed.2015.05.001

30. Eraso FE, Scarfe WC, Hayakawa Y, Goldsmith J, Farman AJ. Teledentistry: protocols for the transmission of digitized radiographs of the temporomandibular joint. J Telemed Telecare. 1996;2(4):217-223.

31. Cederberg RA, Bentley DA, Halpin R, Valenza JA. Use of virtual patients in dental education: a survey of U.S. and Canadian dental schools. J Dent Educ. 2012;76(10):1358-1364. doi: 10.1002/j.00220337.2012.76.10.tb05391.x 
32. Seifert LB, Socolan O, Sader R, Rüsseler M, Sterz J. Virtual patients versus small-group teaching in the training of oral and maxillofacial surgery: a randomized controlled trial. BMC Med Educ. 2019;19(1):454. doi: 10.1186/ s12909-019-1887-1

33. Rahman B, Abraham SB, Alsalami AM, Alkhaja FE, Najem SI. Attitudes and practices of infection control among senior dental students at college of dentistry, university of Sharjah in the United Arab Emirates. Eur J Dent. 2013;7(Suppl 1):S015-S019. doi: 10.4103/13057456.119058

34. Ignatius E, Perala S, Makela K. Use of videoconferencing for consultation in dental prosthetics and oral rehabilitation. J Telemed Telecare. 2010;16:467-470. doi: 10.1258/ jtt.2010.100303

35. Torres-Pereira C, Possebon RS, Simões A, Bortoluzzi MC, Leao JC, Giovanini AF, et al. Email for distance diagnosis of oral diseases: a preliminary study of teledentistry J Telemed Telecare. 2008;14(8):435-438. doi: 10.1258/ jtt.2008.080510

36. Duka M, Mihailovic B, Miladinovic M, Janković A, Vujicić B. Evaluation of Telemedicine Systems for Impacted Third Molars Diagnosis. Vojnosanit Pregl. 2009;66:985-991. doi: 10.2298/vsp0912985d

37. Zivkovic D, Tosic G, Mihailovic B, Miladinović M, Vujičić B. Diagnosis of Periapical Lesions of the Front Teeth Using the Internet. PONS Med J. 2010;7:138-143.

38. Stephens CD, Cook J, Mullings C. Orthodontic referrals via teledent southwest. Dent Clin North Am. 2002;46:507520. doi: 10.1016/s0011-8532(02)00010-1

39. Rocca MA, Kudryk VL, Pajak JC, Morris T. The Evolution of a Teledentistry System within the Department of Defence. Proc AMIA Symp. 1999:921-924.

40. Kopycka-Kedzierawski DT, Billings RJ. Prevalence of dental caries and dental care utilization in pre-schoo urban children enrolled in a comparative-effectiveness study. Eur Arch Paediatr Dent. 2011;12:133-138. doi: 10.1007/BF03262794

\section{Authors' Contribution:}

IF: Conceptualization, Formal Analysis, Investigation, Methodology, Project Administration, Resources, Software, Validation, Writing - Original Draft Preparation, Writing Review \& Editing.

SA: Data Curation, Formal Analysis, Investigation, Methodology, Project Administration, Resources, Software, Writing - Original Draft Preparation, Writing - Review \& Editing.

IAM:Formal Analysis, Investigation, Methodology, Supervision, Validation, Visualization, Writing Original Draft Preparation, Writing - Review \& Editing

JA: Formal Analysis, Investigation, Methodology, Supervision, Validation, Visualization, Writing Original Draft Preparation, Writing - Review \& Editing

IF takes the responsibility and is accountable for all aspects of the work in ensuring that questions related to the accuracy or integrity of any part of the work are appropriately investigated and resolved. 